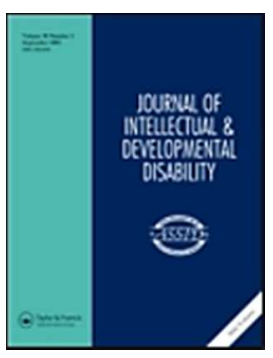

\title{
Arson or fire setting in offenders with intellectual disability: clinical characteristics, forensic histories and treatment outcomes
}

\begin{tabular}{|r|l|}
\hline Journal: & Journal of Intellectual \& Developmental Disability \\
\hline Manuscript ID: & CJID-2014-0037.R1 \\
\hline Manuscript Type: & Research Paper \\
\hline Keywords: & $\begin{array}{l}\text { intellectual disability, learning disability, arson, fire setting, mental health, } \\
\text { secure, forensic, offending }\end{array}$ \\
\hline \multicolumn{2}{|r}{} \\
\hline
\end{tabular}

SCHOLARONE ${ }^{\text {IN }}$

Manuscripts 


\title{
Running head: FIRE SETTING AND INTELLECTUAL DISABILITY \\ Word Count: 3240
}

\section{Arson or fire setting in offenders with intellectual disability: clinical characteristics, forensic histories and treatment outcomes}

\begin{abstract}
Background - Although many with intellectual disability come to the attention of services for fire setting, research in this area is scarce, which poses challenges for management.

Method - This paper examines those with a fire setting history $(\mathrm{n}=30)$, identified from a sample of 138 patients treated in a UK forensic intellectual disability service. Those with a fire setting history were compared to those without this history, on various clinical, forensic and treatment outcome variables.

Results - Fire setting was associated with significant psychopathology, including psychosis and personality disorders. Only half of the fire-setters had a formal arson conviction. Fire setters were more likely to have a violence conviction, and criminal sections / restriction orders.

Conclusions - Half of those with fire setting histories did not have formal arson convictions, highlighting the need for thorough history taking. Prevalent comorbidity suggests interventions should focus on treating psychopathology, before offence specific arson therapies.
\end{abstract}

Keywords - intellectual disability, learning disability, arson, fire setting, mental health, secure, forensic, offending 


\section{FIRE SETTING AND INTELLECTUAL DISABILITY}

\section{Arson or fire setting in offenders with intellectual disability: clinical characteristics, forensic histories and treatment outcomes}

\section{Background}

The setting of fires has devastating human and financial costs. In the UK in 2008, there were 53,000 deliberately set fires, and 451 fire-related deaths (Department for Communities and Local Government, 2010). This resulted in an estimated cost to the economy of $£ 2.53$ billion (Office of the Deputy Prime Minister, 2006). Problems with the accurate estimation of fire setting can arise from the terminology used to describe and classify fire setting behaviour.

The two terms commonly used to describe deliberate fire setting are 'arson' and 'fire setting'. These are often used interchangeably, despite their different definitions. In the UK, arson is defined by Section 1(2) of the criminal Damage Act 1971 as "to destroy or damage property intending thereby to endanger the life of another, or being reckless as to whether the life of another would thereby be endangered" (The Crown Prosecution Service, 2014). The lesser charge of being reckless would apply if intent (to either damage property, or endanger life) cannot be reliably proven. Though definitions of arson vary internationally, arson is treated extremely seriously by criminal justice agencies throughout the world, with sentences for convicted arsonists ranging upwards from ten years to life imprisonment (Curtis, McVilly, \& Day, 2013). This reflects the significant harms associated with arson, and the high costs to the community these offences incur.

Whereas an arsonist is someone who has been convicted of the crime of arson, the term 'fire setting' refers to behaviour characterised by the deliberate setting of fires, which has not led to a conviction. This may be due to difficulty identifying the fire setter, the fire not being detected as deliberate, or causing only minimal damage. 


\section{FIRE SETTING AND INTELLECTUAL DISABILITY}

The perpetrator may be below the age of criminal responsibility, or there is insufficient evidence to gain a conviction. In intellectual disability populations, such offences may also be reported to authorities, but the person may be deemed not guilty because of mental incompetence. Throughout this paper, the term 'arson' will be used to describe those convicted of the crime of arson, and 'fire setting' where there is a record of fire setting behaviour, which has not led to a conviction of arson.

It is often reported that the prevalence of arson and fire setting is higher among people with intellectual disabilities (e.g. Simpson, \& Hogg, 2001). A number of studies have reported the prevalence rates of arson, and fire setting amongst those with intellectual disability, and vice versa (See Table 1). As Table 1 details, these prevalence rates vary widely, particularly between community, and specialist intellectual disability inpatient services. Further, these estimates of prevalence are confounded by numerous methodological issues (Taylor, Thorne, Roberston, \& Avery, 2002; Devapriam, \& Bhaumik, 2012) including variations in the definition of intellectual disability, differences between study settings and the reporting of highly selected populations (e.g. prisons and hospitals). It is noted that those with intellectual disability can have a lesser ability to conceal their actions, and are more likely to be caught and arrested for their crimes when they do occur. On the other hand, what would be classified as a crime and conviction for someone without intellectual disabilities, may often be labelled as 'challenging behaviour' in someone with intellectual disabilities (Emerson, \& Einfield, 2011), as carers can be reluctant to report to authorities for a number of reasons.

\section{Insert Table 1}

There is therefore insufficient evidence to establish whether or not fire setting is over- or under-represented in those with intellectual disability (Holland, Clare, \& 


\section{FIRE SETTING AND INTELLECTUAL DISABILITY}

Mukhopadhyay, 2002). However it is clear that significant numbers of people with intellectual disability come to the attention of health and social, and criminal justice services for reasons of fire setting and arson. Despite these significant numbers, few studies have investigated fire setters in intellectual disability populations. This means that managing the fire setting behaviour of this population can pose significant challenges to services (Lindsay, \& Taylor, 2005). However, a number of servicebased studies have been reported, which have investigated the characteristics of those treated within services for reason of arson and fire setting, and also described treatment approaches.

Devapriam, Raju, Singh, Collacott and Bhaumik, (2007) investigated the prevalence, characteristics and predisposing factors for arson in people with intellectual disability in contact with psychiatric services in Leicestershire in England. The authors reported significant comorbidity amongst those who had committed arson, with high rates of major mental illness, and in particular, personality disorder. Roughly half of the sample had set fires on multiple occasions, and $70 \%$ could be described as versatile offenders, having committed other types of offences. It was also noted that those who had committed arson were not uniformly processed by the criminal justice system, with only a fifth of the group going to prison. The majority received hospital orders, whereas a minority received no sanctions for their actions.

A number of studies have described psychological interventions for the treatment of fire setting behaviour. Taylor et al (2002) evaluated the impact of a broadly cognitive behavioural, 40-session group-based intervention on 14 men and women with mild and borderline intellectual disability, who had convictions for arson and were detained in a hospital low secure service. The treatment aimed to reduce fire interest and attitudes associated with fire-setting behaviour. Participants were assessed 
FIRE SETTING AND INTELLECTUAL DISABILITY

pre- and post-treatment on a number of fire-specific, anger, self-esteem and depression measures. Following treatment, significant improvements were found in all areas assessed, excepting depression. Performances on these measures over a longer follow up period were not reported.

The same group of authors (Taylor et al., 2006) reported a study on a group of six women detained in a specialist forensic intellectual disability service in England. Although pre and post measures of fire setting interest and attitudes were taken, the sample size was too small to determine whether the treatment had any significant group effect. Therefore the authors qualitatively described the treatment reports of each individual engaged in treatment, as well as a two-year follow up of any recorded fire setting behaviour in the individuals discharge placement. All but one of the participants were recidivist fire-setters, and several had set tens of fires in the past. Five of the six study participants had moved from secure to open community placements following completion of the programme and none were reported to have set any fires at 2-year follow-up, although those discharged continued to receive staff support and supervision to varying degrees. Although the authors note the drawbacks of their study, they concluded that female fire-setters with intellectual disabilities can successfully engage in and benefit from therapy, reflected by an absence of firesetting behaviour in the short to medium term.

Studies have investigated the clinical and forensic characteristics of arsonists and fire-setters in general mental health populations. Tyler and Gannon (2012) recently reviewed the literature on male fire setters with mental disorder, and comprehensively described the socio-demographic, developmental, personality, neuropsychological and biological factors associated with this behaviour (See Box 1). Arguably, many of these factors (deprived social backgrounds, disruptive childhoods, 
FIRE SETTING AND INTELLECTUAL DISABILITY

sexual and physical abuse, poor social skills, etc.) are not specific to fire setters and may be found in other offender groups.

\section{Insert Box 1}

This paper aims to investigate the clinical, forensic and treatment outcome variables associated with those with a history of fire setting behaviour treated in a forensic hospital setting for people with intellectual disability. Those with a history of fire setting will also be compared to those without on the same variables.

\section{Method}

This study was part of a wider service evaluation project of a 64 bedded specialised forensic inpatient service in England, for people with mild intellectual disability and offending behaviour. All inpatients treated within the service over a 6year period were included in the study. Retrospective data collection from the case files was done by three authors (R.A., I.G., S.H.) who had treated these patients in their capacity as Consultant Psychiatrists. Definitions of the variables, and how each was measured are as follows:

\section{Clinical variables}

Age and Gender: Patients' age and gender were recorded.

Diagnosis: The service had an established structure of assessments (Selby, \& Alexander, 2004) and used ICD-10 diagnostic criteria to generate a diagnosis for each patient (World Health Organization, 1992). This covered the degree and cause of ID, pervasive developmental (autistic spectrum) disorders, personality disorders, mental illnesses, harmful use or dependence on alcohol or illicit drugs, physical disorders, psychosocial factors and behavioural problems. While not adopting the hierarchical approach to differential diagnosis of behavioural difficulties favoured by the Diagnostic Criteria - Learning Disability, this system nevertheless captures the 


\section{FIRE SETTING AND INTELLECTUAL DISABILITY}

extensive comorbidity experienced by offenders with ID (DC-LD; Royal College of Psychiatrists, 2001).

The presence of abuse: Evidence of either a child protection, or protection of a vulnerable adult response by social services had to be present before the experience of abuse was recorded as either probable or definite. This approach is similar to that adopted by Flynn, Matthews, and Hollins (2002).

\section{Forensic variables}

Type of detention: All patients admitted to the service are detained under the Mental Health Act 1983 for England and Wales. Although all patients had some type of offending behaviour, not all had been through the criminal justice process. For the study, Sections 35-38, 47 and 48 of the Mental Health Act, where the detention order is made either by a court or by the Ministry of Justice were designated as 'criminal sections'. In addition, the study recorded the presence of any 'restriction orders', a provision under the Mental Health Act 1983 where the power to discharge patients is taken away from the treating clinician and given to either Mental Health Review Tribunals or the Ministry of Justice.

Past convictions: Three categories of past convictions were recorded; violence offences (those involving interpersonal violence), sexual offences and arson offences.

Past history of aggression: Patients' histories of aggression were recorded (as present or absent) according to six parameters: verbal aggression, aggression to people, aggression to property, aggression to self, sexual aggression and history of fire setting.

Arson / Fire Setting definition - The two terms commonly used to describe deliberate fire setting are 'arson' and 'fire setting'. These are often used 
FIRE SETTING AND INTELLECTUAL DISABILITY

interchangeably, despite their different definitions. The present study covers both those with a history of fire setting, and those convicted of arson. A fire setting history was defined as the presence of any type of fire setting behaviour recorded within the patient's case history. This was to capture those whose fire setting behaviour had not been processed by the criminal justice system, as well as those with a recorded arson offence.

\section{Treatment outcome variables}

Institutional aggression: Use of seclusion, physical intervention and intensive observation periods were used as proxy measures for institutional aggression. Data on these interventions was only available for 113 patients treated within the first 4 years covered by the study. The total number of each intervention was divided by the total number of months of inpatient stay for each patient, and an average monthly intervention figure was generated.

Length of stay and direction of care pathway: For the 77 patients who were discharged from the service during the study period, the average duration of hospital stay and a measure of treatment success was gathered. Treatment success was defined by whether the patient was discharged to a setting of a lower level of security. A 'poor' outcome was defined as a discharge to a setting of the same or a higher level of security.

\section{Ethics}

Ethical approval was sought from the Norfolk (1) Research Ethics Committee which advised the project did not need to be ethically reviewed under the terms of the Governance Arrangements for Research Ethics Committees in the UK, as it was service development. Findings from the project and the method have been described earlier (Alexander, Green, O’Mahony, Gunaratna, Gangadharan, \& Hoare, 2010). 
FIRE SETTING AND INTELLECTUAL DISABILITY

\section{Statistical analysis}

Those with a fire setting history were compared to those without a fire setting history on a number of clinical, forensic and treatment outcome variables. Chi-square and Fishers exact tests were used for comparison of categorical variables and MannWhitney U-test for comparison of means. Non-parametric tests were used when data did not meet the statistical assumptions for parametric tests. Data was analysed using SPSS - Version 20.

\section{Results}

There were a total of 138 patients, 109 men and 29 women. Of this group, 30 had a history of fire setting, a prevalence of approximately $22 \%$. Those with a fire setting history $(n=30)$ were compared to those without $(n=108)$.

Table 2 shows the comparison between the two groups on the clinical variables measured. Of the fire setting group, $80 \%(n=24)$ had a personality disorder (dissocial or emotionally unstable), $70 \%(n=21)$ had experienced abuse, $46 \%(n=$ 14) a major mental illness (psychosis, bipolar disorder or major depression), $40 \%(n=$ 12) harmful use or dependence on alcohol and / or illicit drugs and 20\% $(n=6)$ a pervasive developmental (autistic spectrum) disorder. The experience of abuse ( $p=$ $0.026)$ and a diagnosis of personality disorder $(p=0.03)$ were significantly more common in the fire setting group.

\section{Insert Table 2}

Table 3 highlights variables related to the patients' forensic histories and offending behaviours. Of the 30 fire setters, only 14 (47\%) had received a criminal conviction for arson. Fire setters were more likely than the non-fire setters to have had a past violence conviction $(p=.007)$, while there were no differences on past convictions for sexual offences. 


\section{FIRE SETTING AND INTELLECTUAL DISABILITY}

\section{Insert Table 3}

Table 4 displays the comparisons between groups upon the three measures of treatment outcome; institutional aggression, duration of hospital stay and direction of the care pathway. There were no significant differences between groups on measures of institutional aggression. The findings related to length of stay and direction of care pathway should be treated with caution, due to the small numbers of discharged patients within the fire setting group. Of the 30 fire setters treated over the six year period covered by the study, eight were discharged. These patients appear to have had a length of stay significantly shorter than that of the non-fire setter group. All eight had a good outcome, with two going into the community on a guardianship order and the other six to hospital settings of a lower level of security. However, when looking at the group of patients who had not yet been discharged, there were no significant differences between the two groups on length of stay.

\section{Insert Table 4}

\section{Discussion}

This service evaluation paper provides a preliminary exploration of the clinical, forensic and treatment outcome factors associated with fire setters and arsonists admitted to one forensic intellectual disability service in the UK. There are a number of limitations of the study. The service evaluation methodology meant only routinely collected retrospective data could be included, which limited the number of variables which could be examined. Future, prospective work could focus on examining hypotheses driven by previous research, e.g. Tyler and Gannon (2012). The sample was drawn from a single service and hence one needs to be cautious about the generalisability of the findings. Replicating this process in a prospective manner, 
FIRE SETTING AND INTELLECTUAL DISABILITY

involving more services on a regional or national basis would help further our understanding of this group.

However, the data reflects the clinical and forensic characteristics, and treatment outcomes of patients with a history of fire setting, treated over a six year period, about which there is very limited published literature. Findings provide an insight into the differences and similarities between fire setters and non-fire setters in this population, and are discussed in reference to populations without intellectual disability, as reported in previous research.

The key finding of the study was that fire setting behaviour amongst this population was associated with extensive psychiatric co-morbidity. While all patients had an intellectual disability, there was also very high prevalence of personality disorder, major mental illness, harmful use of alcohol / illicit drugs, and autistic spectrum disorder. The fire setting group had experienced significantly more physical and sexual abuse than those without a fire setting history. Increased rates of morbidity in fire setters have been described previously (Devapriam, Raju, Singh, Collacott, \& Bhaumik, 2007; Tyler, \& Gannon, 2012). The available data did not allow us to tease out whether fire-setting was directly related to the psychopathology associated with these diagnoses. This may be something to explore in studies with larger sample sizes, drawn from multiple sites. Clarifying that relationship will help to decide whether the focus of treatment needs to be the co-morbid mental health condition rather than the offence-specific therapeutic work, or a combination of both.

As reported in previous research (e.g. Taylor, et al., 2006; Devapriam, Raju, Singh, Collacott, \& Bhaumik, 2007), less than half of those with a fire setting history had a conviction for arson. This is probably because the blurred dividing line between criminal, and challenging behaviour in people with intellectual disability, which 


\section{FIRE SETTING AND INTELLECTUAL DISABILITY}

affects the reporting and recording of such behaviour (Holland, Clare, \&

Mukhopadhyay, 2002). This finding underscores the importance of systematic history taking when undertaking risk assessment for individuals with intellectual disability.

The fire-setting group had significantly more violence convictions than those

in the non-fire-setting group. There were no differences between groups regarding their past histories of aggression, or institutional aggression, with rates equally high in both groups. These findings contrast with earlier conceptualisations of arsonists and fire setters, as unlikely to engage in interpersonal violence, due to the passive conflict management strategies typical of this group (Jackson, Hope, \& Glass, 1987; Tyler, \& Gannon, 2012). Indeed, past authors have described fire setters and arsonists as 'model prisoners' for this reason (Hurley, \& Monahan, 1969). It is unclear whether these findings relate to the nature of this particular sample, e.g., due to the high prevalence of personality disorder. At present, there are no existing studies from forensic intellectual disability services available for comparison, although studies from community intellectual disability settings report a high proportion of the fire setters committing other types of offences (Devapriam, Raju, Singh, Collacott, \& Bhaumik, 2007).

Rates of arson and fire setting within forensic intellectual disability services are high, demonstrating a clear treatment need. A number of psychological treatment groups for people with intellectual disability and fire setting behaviour have been reported (e.g. Taylor et al., 2002; Jervis, 2012; Tranah, \& Nicholas, 2013). However, the high prevalence of psychiatric morbidity in this sample, such as schizophrenia raises questions about the most appropriate sequence of therapeutic interventions. Within the service where the study took place, patients progress through a ten-point treatment programme (see Box 2). This approach is based on the treatment pathway 


\section{FIRE SETTING AND INTELLECTUAL DISABILITY}

for the management of personality disorders in learning disability, suggested by Johnstone (2005), who described a four stage process consisting of assessment and motivational work, interventions including foundation treatments, offence specific treatments and personality disorder symptom reduction treatments, consolidation or relapse prevention and discharge. The programme emphasises the treatment of comorbid conditions prior to any further work, and introduces participants to strategies and skills to assist with deficits like poor social skills, low self-esteem, poor emotional regulation and problematic interpersonal relationships before starting any offence specific work (e.g. fire setting and arson treatment programmes).

Of the 30 fire setters treated over the six year period covered by the study, eight were discharged. These patients had significantly lower length of stays than the non-fire setters and were successfully discharged to lower levels of security. This could suggest that there may be a sub-group of those with a history of fire setting within this population who respond well to treatment. However, there was a larger group with longer lengths of stay, who remained as inpatients. The distinction between these two groups and their different treatment needs requires further exploration. It is therefore recommended that future research investigate this issue, with larger samples drawn from multiple services.

\section{References}

Alexander, R. T., Crouch, K., Halstead, S., \& Piachaud, J. (2006). Long-term outcome from a medium secure service for people with intellectual disability. Journal of Intellectual Disability Research, 50(4) 305-315. doi: 10.1111/j.13652788.2006.00806.x

Alexander, R. T., Green, F. N., O’Mahony, B., Gunaratna, I. J., Gangadharan, S. K., \& Hoare, S. (2010). Personality disorders in offenders with intellectual 
FIRE SETTING AND INTELLECTUAL DISABILITY

disability: a comparison of clinical, forensic and outcome variables and implications for service provision. Journal of Intellectual Disability Research, 54(7) 650-658. doi: 10.1111/j.1365-2788.2010.01248.x

Alexander, R. T., Hiremath, A., Chester, V., Green, F. N., Gunaratna, I. J., \& Hoare, S. (2011). Evaluation of treatment outcomes from a medium secure unit for people with intellectual disability. Advances in Mental Health and Intellectual Disabilities, 5(1) 22-32. doi: 10.5042/amhid.2011.0013

Alexander, R. T., Piachaud, J., Odebiyi, L., \& Gangadharan, S. K. (2002). Referrals to a forensic service in the psychiatry of learning disability. British Journal of Forensic Practice, 4, 29-33. doi: 10.1108/14636646200200013

Alexander, R. T., Tajuddin, M., \& Gangadharan, S. (2007). Personality Disorders in Intellectual Disability: Approaches to Pharmacotherapy. Mental Health Aspects of Developmental Disabilities, 10(4) 129-135.

Bhaumik, S., \& Branford, D. (2005). The Frith Prescribing Guidelines for Adults with Learning Disability. Oxfordshire: Taylor and Francis.

Curtis, A., McVilly, K., \& Day, A. (2012). Arson treatment programmes for offenders with disability: a systematic review of the literature. Journal of Learning Disabilities and Offending Behaviour, 3(4) 186-205. doi: $10.1108 / 20420921211327347$

Department for Communities and Local Government. (2010). Fire Statistics United Kingdom 2008. Retrieved Dec $5^{\text {th }}, 2012$, from http://www.communities.gov.uk/documents/statistics/pdf/1780609.pdf

Devapriam, J., \& Bhaumik, S. (2012). Intellectual disability and arson. In G. L. Dickens, P. A. Sugarman \& T. A. Gannon (Eds.), Fire Setting and Mental Health (pp. 107-125). London: RCPsych Publications. 


\section{FIRE SETTING AND INTELLECTUAL DISABILITY}

Emerson, E., \& Einfeld, S. L. (2011). Challenging behaviour: analysis and intervention in people with intellectual disabilities. Cambridge: Cambridge University Press.

Enayati, J., Grann, M., Lubbe, S., \& Fazel, S. (2008). Psychiatric morbidity in arsonists referred for forensic psychiatric assessment in Sweden. The Journal of Forensic Psychiatry \& Psychology, 19(2) 139-147. doi:

$10.1080 / 14789940701789500$

Flynn, A., Matthews, H., \& Hollins, S. (2002). Validity of the diagnosis of personality disorder in adults with learning disability and severe behavioural problems: Preliminary study. British Journal of Psychiatry, 180, 543-546. doi: 10.1192/bjp.180.6.543

Hogue, T., Steptoe, L., Taylor, J. L., Lindsay, W. R., Mooney, P., Pinkney, L. . . . O'Brien, G. (2006). A comparison of offenders with intellectual disability across three levels of security. Criminal Behaviour and Mental Health, 16(1) $13-28$.

Holland, T., Clare, I., \& Mukhopadhyay, T. (2002). Prevalence of 'criminal offending' by men and women with intellectual disability and the characteristics of 'offenders': Implications for research and service development. Journal of Intellectual Disability Research, 46, 6-20. doi: $10.1002 / \mathrm{cbm} .52$

Hearne, S. Garner, K., O’Mahony, B., Thomas, C., \& Alexander, R.T. (2007). The Life Skills group - an introductory multi-modular group programme in forensic learning disability. The British Journal of Forensic Practice, 9(2) 313. doi: $10.1108 / 14636646200700008$ 
FIRE SETTING AND INTELLECTUAL DISABILITY

Hurley, W., \& Monahan, T. M. (1969). Arson: the criminal and the crime. British Journal of Criminology, 9, 4-21.

Jackson, H. F., Hope, S., \& Glass, C. (1987). Why Are Arsonists Not Violent Offenders? International Journal of Offender Therapy and Comparative Criminology, 31, 143-151. doi: 10.1177/0306624X8703100207

Jervis, V. (2012, April). Development of the Phoenix Fire Setting Group. Paper session at the 11th International Conference on the Care and Treatment of Offenders with a Learning Disability, Northumbria University.

Johnstone, S. (2005, April). Intellectually disabled offenders with personality disorder. Paper session at the 4th International Conference on the Care and Treatment of Offenders with a Learning Disability, University of Central Lancashire, Preston.

Lindsay, W. R., \& Taylor, J. L. (2005). A selective review of research on offenders with developmental disabilities: Assessment and treatment. Clinical Psychology and Psychotherapy, 12, 201-214. doi: 10.1002/cpp.450

Lindsay, W., Carson, D., O'Brien, G., Holland, A. J., Johnstone, S., Taylor, J. L., . . . Young, S. (2010). The relationship between assessed risk and service security level for offenders with intellectual disability. The Journal of Forensic Psychiatry \& Psychology, 21(4) 537-548. doi: 10.1080/14789941003653212

Office of the Deputy Prime Minister. (2003). Arson Control Forum annual report. London: Author.

Plant, A., McDermott, E., Chester, V., \& Alexander, R.T. (2011). Substance misuse among offenders in a forensic intellectual disability service. Journal of Learning Disabilities and Offending Behaviour, 2(3) 127-136. doi: $10.1108 / 20420921111186589$ 


\section{FIRE SETTING AND INTELLECTUAL DISABILITY}

Petty, M., Rolfe, J., \& Chester, V. (2013). Moving from feelings of terror to 'I like learning maths': An evaluation of a teaching activity in a forensic intellectual disability setting. Quality Network for Forensic Mental Health Low Secure Newsletter, Issue 3, 3-5.

Puri, B. K., Baxter, R., \& Cordess, C. C. (1995). Characteristics of fire-setters. A study and proposed multiaxial psychiatric classification. The British Journal of Psychiatry, 166(3) 393-396. doi: 10.1192/bjp.166.3.393

Royal College of Psychiatrists (2001). DC-LD: Diagnostic criteria for psychiatric disorders for use with adults with learning disabilities/mental retardation. London: Author.

Selby, G., \& Alexander, R. T. (2004). Care programme approach in a forensic learning disability service. The British Journal of Forensic Practice, 6(4) 2631. doi: $10.1108 / 14636646200400024$

Simpson, M. K., \& Hogg, J. (2001). Patterns of offending among people with intellectual disability: a systematic review. Part I: methodology and prevalence data. Journal of Intellectual Disability Research, 45(5) 385-396.

Smith, A., Petty, M., Oughton, I., \& Alexander, R. T. (2010). Establishing a workbased learning programme: vocational rehabilitation in a forensic learning disability setting. British Journal of Occupational Therapy, 73(9) 431-436. doi: 10.4276/030802210X12839367526174

Taylor, J. L., Thorne, I., Roberston, A., \& Avery, G. (2002). Evaluation of a group intervention for convicted arsonists with mild and borderline intellectual disabilities. Criminal Behaviour and Mental Health, 12, 282-293. doi: 10.102/cbm.506 


\section{FIRE SETTING AND INTELLECTUAL DISABILITY}

Taylor, J. L., Robertson, A., Thorne, I., Belshaw, T., \& Watson, A. (2006). Responses of Female Fire-Setters with Mild and Borderline Intellectual Disabilities to a Group Intervention. Journal of Applied Research in Intellectual Disabilities, 19, 179-190. doi: 10.1111/j.1468-3148.2005.00260.x

The Crown Prosecution Service (2014). Criminal Damage. Available from: http://www.cps.gov.uk/legal/a_to_c/criminal_damage/\#a14 Accessed $2^{\text {nd }}$ June 2014.

Thomas, C., Kitchen, D., \& Smith, A. (2005). The management of aggression care plans: implementation and efficacy in a forensic learning disability service. The British Journal of Forensic Practice, 7(2) 3-9. doi: $10.1108 / 14636646200500008$

Tranah, T., \& Nicholas, J. (2013). Interventions for young people with intellectual disabilities who commit arson. Advances in Mental Health and Intellectual Disabilities, 7(2) 72-81. doi: 10.1108/20441281311310162

Tyler, N., \& Gannon, T. A. (2012). Explanations of firesetting in mentally disordered offenders: A review of the literature. Psychiatry, 75(2) 150-66. doi: 10.1521/psyc.2012.75.2.150

Wheeler, J. R., Holland, A. J., Bambrick, M., Lindsay, W. R., Carson, D., Steptoe, L., .. O'Brien, G. (2009). Community services and people with intellectual disabilities who engage in antisocial or offending behaviour: referral rates, characteristics, and care pathways. Journal of Forensic Psychiatry \& Psychology, 20(5) 717-740. doi: 10.1080/14789940903174048

World Health Organization. (2008). ICD-10: International statistical classification of diseases and related health problems (10th Rev. ed.). New York, NY: WHO. 


\section{FIRE SETTING AND INTELLECTUAL DISABILITY}

Table 1: Reported Prevalence of Arson and Fire Setting in Intellectual Disability Populations.

\begin{tabular}{|c|c|c|c|c|c|}
\hline Study & Sample / Population & $\begin{array}{c}\text { Total } \\
n\end{array}$ & Country & Definition & $\begin{array}{l}\text { Reported } \\
\text { Prevalence }\end{array}$ \\
\hline Puri et al. (1995) & $\begin{array}{l}\text { People with intellectual disability referred to a forensic } \\
\text { psychiatry service }\end{array}$ & 36 & England & Fire-setting & $3 \%$ \\
\hline Taylor (2002) & $\begin{array}{l}\text { Men with intellectual disability admitted to an inpatient forensic } \\
\text { service }\end{array}$ & 129 & England & Arson & $25 \%$ \\
\hline Alexander et al. (2002) & Referrals to a forensic intellectual disability service & 79 & England & Arson & $10.4 \%$ \\
\hline Alexander et al. (2006) & $\begin{array}{l}\text { Inpatients discharged from a medium secure intellectual } \\
\text { disability service. }\end{array}$ & 64 & England & Arson & $15 \%$ \\
\hline Hogue et al. (2006) & $\begin{array}{l}\text { Offenders with intellectual disability from three levels of } \\
\text { security, medium (M), low (L), community (Com). }\end{array}$ & 212 & $\begin{array}{l}\mathrm{UK}-3 \\
\text { regions }\end{array}$ & Arson & $\begin{array}{l}\mathrm{M} / \mathrm{L}-21.4 \% \\
\mathrm{Com}-2.9 \%\end{array}$ \\
\hline Devapriam et al. (2007) & $\begin{array}{l}\text { Adults }(19+) \text { with intellectual disability who had been in contact } \\
\text { with community psychiatric services during a } 20 \text { year period. }\end{array}$ & 1100 & England & Arson & $1.36 \%$ \\
\hline Enayati et al. (2008) & $\begin{array}{l}\text { Arsonists referred for inpatient forensic psychiatric examination } \\
\text { over a five-year period (1997-2001). }\end{array}$ & 214 & Sweden & Arson & $9.8 \%$ \\
\hline Wheeler et al. (2009) & Referrals to community learning disability team. & 237 & $\begin{array}{l}\mathrm{UK}-3 \\
\text { regions }\end{array}$ & Fire starting & $1 \%$ \\
\hline $\begin{array}{l}\text { Alexander et al. (2010; } \\
\text { 2011) }\end{array}$ & Secure / forensic inpatient intellectual disability service & 138 & England & $\begin{array}{l}\text { Arson } \\
\text { Fire setting }\end{array}$ & $\begin{array}{l}10 \% \\
22 \%\end{array}$ \\
\hline Lindsay et al. (2010) & $\begin{array}{l}\text { Offenders with intellectual disability accepted into forensic } \\
\text { services }\end{array}$ & & & Fire setting & $10 \%$ \\
\hline
\end{tabular}




\section{FIRE SETTING AND INTELLECTUAL DISABILITY}

Table 2: Comparison between those with Fire Setting histories and those Without: Clinical Variables

\begin{tabular}{cccc}
\hline Examined measure & History of & No fire setting & Statistical test \\
history & OR (95\% CI) \\
& $n(\%)$ & $n(\%)$ & \\
\hline
\end{tabular}

No. of patients $(\mathrm{n}=138$, available data $-n=135)$

Age on admission $\neq$ (Median, Mean, (s.d.))

Gender $\uparrow$

Male

Female

Past experience of abuse $\dagger$

Any abuse

Any sexual abuse

Diagnostic comorbidity $\dagger$

Pervasive developmental disorders

Psychosis

Bipolar disorders

Depressive disorders

Harmful use or dependence on substances

Personality Disorder (either Dissocial or Emotionally

unstable)

Dissocial Personality Disorder

Emotionally Unstable Personality Disorder

Epilepsy

$\neq$ Mann-Whitney Test

†Fishers Exact Test

\section{5}

$27,29.23(9.19) \quad 30,30.69(9.266) \quad U=1434, z=-.747, \quad$ n.s.

$22(74 \%) \quad 85(81 \%) \quad \chi^{2}(1)=0.824, \quad$ n.s.

$8(26 \%) \quad 20(19 \%)$

$21(70 \%)$

$16(53 \%)$

$6(20 \%)$

$7(23 \%)$

$1(3 \%)$

$6(20 \%)$

$12(40 \%)$

$24(80 \%)$
$22(73 \%)$
$16(53 \%)$
$1(3 \%)$

$47(45 \%)$

$39(37 \%)$

$\chi^{2}(1)=5.945$,

$\chi^{2}(1)=2.533$,

$p<.05$

n.s.

$35(33 \%)$

$19(15 \%)$

$\chi^{2}(1)=1.962$,

$\chi^{2}(1)=0.412$,

$\chi^{2}(1)=2.362$,

$\chi^{2}(1)=0.361$,

$16(15 \%)$

$\chi^{2}(1)=2.318$,

$\chi^{2}(1)=8.808$,

$52(49 \%)$

$\chi^{2}(1)=8.669$

$\chi^{2}(1)=13.031$,

$21(20 \%)$

$20(19 \%)$ n.s.

$$
\text { n.s. }
$$

n.s.

n.s

n.s.

$p<.05$

$4.1(1.5-10.8)$

$p<.05 \quad 3.7(1.5-9)$

$p<.001 \quad 4.6(1.9-10.8)$

$p<.05$

$0.1(0-1.1)$ 


\section{FIRE SETTING AND INTELLECTUAL DISABILITY}

Table 3: Comparison between those with Fire Setting Histories and those Without: Forensic variables

\begin{tabular}{|c|c|c|c|c|c|}
\hline Examined measure & $\begin{array}{l}\text { History of } \\
\text { fire setting } \\
\quad n(\%)\end{array}$ & $\begin{array}{c}\text { No fire } \\
\text { setting } \\
\text { history } \\
n(\%) \\
\end{array}$ & Statistical te & & OR $(95 \% \mathrm{CI})$ \\
\hline $\begin{array}{l}\text { Number of patients } \\
(n=138, \text { available data }-n=135)\end{array}$ & 30 & 105 & & & \\
\hline $\begin{array}{l}\text { Legal status on admission } \dagger \\
\text { Detentions under 'criminal' sections } \\
\text { Detentions with a restriction order }\end{array}$ & $\begin{array}{l}18(60 \%) \\
10(33 \%)\end{array}$ & $\begin{array}{l}35(33 \%) \\
15(14 \%)\end{array}$ & $\begin{array}{l}\chi^{2}(1)=6.958 \\
\chi^{2}(1)=5.610\end{array}$ & $\begin{array}{l}p<.05 \\
p<.05\end{array}$ & $\begin{array}{l}3(1.3-6.9) \\
3(1.2-7.6)\end{array}$ \\
\hline $\begin{array}{l}\text { History of convictions } \dagger \\
\text { Conviction for violence offences } \\
\text { Conviction for sex offences } \\
\text { Conviction for arson }\end{array}$ & $\begin{array}{l}18(60 \%) \\
6(20 \%) \\
14(47 \%)\end{array}$ & $\begin{array}{c}34(14 \%) \\
22(21 \%) \\
0\end{array}$ & $\begin{array}{l}\chi^{2}(1)=7.312 \\
\chi^{2}(1)=0.019 \\
\chi^{2}(1)=54.669\end{array}$ & $\begin{array}{l}p<.05 \\
\text { n.s. } \\
p<.001\end{array}$ & $3.1(1.4-7.2)$ \\
\hline $\begin{array}{l}\text { History of aggression } \dagger \\
\text { Verbal aggression } \\
\text { Aggression towards people } \\
\text { Aggression towards property } \\
\text { History of sexual aggression } \\
\text { Aggression towards self }\end{array}$ & $\begin{array}{l}29(97 \%) \\
26(87 \%) \\
25(83 \%) \\
19(63 \%) \\
27(90 \%)\end{array}$ & $\begin{array}{l}100(95 \%) \\
98(93 \%) \\
97(92 \%) \\
50(48 \%) \\
83(79 \%)\end{array}$ & $\begin{array}{l}\chi^{2}(1)=0.112 \\
\chi^{2}(1)=1.386 \\
\chi^{2}(1)=2.195 \\
\chi^{2}(1)=2.306 \\
\chi^{2}(1)=1.855\end{array}$ & $\begin{array}{l}\text { n.s. } \\
\text { n.s. } \\
\text { n.s. } \\
\text { n.s. } \\
\text { n.s. }\end{array}$ & \\
\hline
\end{tabular}

$\dagger$ †isher's Exact Test 


\section{FIRE SETTING AND INTELLECTUAL DISABILITY}

Table 4: Comparison between those with Fire Setting Histories and those Without: Treatment Outcome Variables

\begin{tabular}{|c|c|c|c|c|c|}
\hline Examined measure & $\begin{array}{l}\text { History of fire setting } \\
\text { median, mean, (s.d.) }\end{array}$ & $\begin{array}{l}\text { No fire setting history } \\
\text { median, mean, (s.d.) }\end{array}$ & \multicolumn{2}{|l|}{ Statistical test } & OR $(95 \% \mathrm{CI})$ \\
\hline \multicolumn{6}{|l|}{ Institutional aggression $\neq(n=112)$} \\
\hline Use of physical intervention & $.59,2.71,(6.19)$ & $.26,3.91,(3.91)$ & $U=777.5, \mathrm{z}=-1.781$ & n.s. & \\
\hline Use of seclusion & $.18, .97,(2.0)$ & $.00, .77,(2.04)$ & $U=722, \mathrm{z}=-2.167$ & n.s. & \\
\hline Use of observation & $2.1,4.49,(6.3)$ & $.80,2.37,(3.74)$ & $U=781.0, \mathrm{z}=-1.748$ & n.s. & \\
\hline Use of pro re nata $(\mathrm{PRN})$ medication & $2.44,4.52,(5.82)$ & $1.52,3.82,(5.66)$ & $U=915, \mathrm{z}=-.74$ & n.s. & \\
\hline Outcomes - discharged patients $\neq(n=77)$ & $n=8$ & $n=66$ & & & \\
\hline Length of stay in days & $705.5,950.4(534.8)$ & $1085.5,1451.6(1051.9)$ & $U=190, \mathrm{z}=-1.288$ & n.s. & \\
\hline Care pathway: good outcome & $8(100 \%)$ & $58(88 \%)$ & $U=232, \mathrm{z}=-1.036$ & n.s. & \\
\hline Community- informal & 0 & $13(20 \%)$ & $U=212, \mathrm{z}=-1.373$ & n.s. & \\
\hline Community- guardianship & $2(25 \%)$ & $4(7 \%)$ & $U=210, \mathrm{z}=-2.162$ & $p<.05$ & $5.2(0.8-34.3)$ \\
\hline Community- supervised discharge & 0 & $4(7 \%)$ & $U=248, \mathrm{z}=-.711$ & n.s. & \\
\hline Hospital section & $6(75 \%)$ & $43(65 \%)$ & $U=238, \mathrm{z}=-.552$ & n.s. & \\
\hline Outcomes - non-discharged patients $\neq(n=58)$ & $n=22$ & $n=39$ & & & \\
\hline Length of stay in days & $1306,1714.6(1483.2)$ & $1299,1726.4(1545.4)$ & $U=423, \mathrm{z}=-.09$ & n.s. & \\
\hline
\end{tabular}

\#Mann-Whitney Test 
FIRE SETTING AND INTELLECTUAL DISABILITY

Box 1: Factors associated with fire setting in offenders with mental disorders (Tyler \& Gannon, 2012).

\section{Socio-demographic \\ Caucasian \\ Single/Separated \\ Low IQ}

Low socioeconomic status

Low levels of educational attainment

Unemployed/unskilled employment

\section{Background/Developmental}

Large family

Absent father

History of physical/sexual abuse

Parental alcoholism

Previous engagement with mental health services

History of truanting from school

Previous convictions for fire-setting

History of juvenile fire-setting

History of parental mental illness

Personality \& Other Associated Traits

Lack social skills

Relationship difficulties

Low levels of assertiveness

Low levels of intelligence

Low self esteem

Impulsive

Low levels of interpersonal aggression

Neuropsychological \& Biological

Klinefelter's syndrome

Reactive hypoglycemic levels

Decreased blood glucose levels

Epilepsy

Neurotransmitter abnormality

Brain injury

Low MHPG Levels

Abnormal EEG readings

\section{Psychosis \& Psychiatric Diagnosis}

Depression

Schizophrenia and other psychotic disorders

Mania

Borderline \& Antisocial Personality Disorders

Developmental Disorders

Bipolar 
FIRE SETTING AND INTELLECTUAL DISABILITY

\section{Box 2: The Ten Point Treatment Plan}

1. A multi-axial diagnostic assessment that covers the degree of learning disability, cause of learning disability, pervasive developmental disorders, other developmental disabilities, mental illnesses, substance misuse or dependence, personality disorders, physical disorders, psychosocial disadvantage and types of behavioural problems (Selby, \& Alexander, 2004)

2. A psychological formulation, developed collaboratively with the patient.

3. Risk assessments (Selby, \& Alexander, 2004)

4. A management of aggression care plan (Thomas, Kitchen, \& Smith, 2005)

5. Appropriate pharmacotherapy that targets both co-morbid mental illnesses and the predominant symptom clusters that are problematic (Bhaumik, \& Branford, 2005; Alexander, Tajuddin, \& Gangadharan, 2007)

6. Treatment of any physical disorders.

7. Individual or group psychotherapy that may include motivational work, supportive therapy, addressing co-morbidities like substance misuse or issues like bereavement and other "foundation treatments" (Hearne, Garner, O’Mahony, Thomas, \& Alexander, 2007; Plant, McDermott, Chester, \& Alexander, 2009)

8. Offence specific therapies, education, skills acquisition and occupational/vocational rehabilitation: (Smith, Petty, Oughton, \& Alexander, 2010; Petty, Rolfe, \& Chester, 2013).

9. Community participation through a system of graded escorted, shadowed and unescorted leave periods

10. Preparation for transition. 


\title{
Running head: FIRE SETTING AND INTELLECTUAL DISABILITY
}

Word Count: 3240

\section{Arson or fire setting in offenders with intellectual disability: clinical characteristics, forensic histories and treatment outcomes}

\begin{abstract}
Background - Although many with intellectual disability come to the attention of services for fire setting, research in this area is scarce, which poses challenges for management.

Method - This paper examines those with a fire setting history $(\mathrm{n}=30)$, identified from a sample of 138 patients treated in a UK forensic intellectual disability service. Those with a fire setting history were compared to those without this history, on various clinical, forensic and treatment outcome variables.

Results - Fire setting was associated with significant psychopathology, including psychosis and personality disorders. Only half of the fire-setters had a formal arson conviction. Fire setters were more likely to have a violenceł conviction, and criminal sections / restriction orders.

Conclusions - Half of those with fire setting histories did not have formal arson convictions, highlighting the need for thorough history taking. Prevalent comorbidity suggests interventions should focus on treating psychopathology, before offence specific arson therapies.
\end{abstract}

Keywords - intellectual disability, learning disability, arson, fire setting, mental health, secure, forensic, offending 
FIRE SETTING AND INTELLECTUAL DISABILITY

\section{Arson or fire setting in offenders with intellectual disability: clinical characteristics, forensic histories and treatment outcomes}

\section{Background}

The setting of fires has devastating human and financial costs. In the UK in 2008, there were 53,000 deliberately set fires, and 451 fire-related deaths (Department for Communities and Local Government, 2010). This resulted in an estimated cost to the economy of $£ 2.53$ billion (Office of the Deputy Prime Minister, 2006). Problems with the accurate estimation of fire setting can arise from the terminology used to describe and classify fire setting behaviour.

The two terms commonly used to describe deliberate fire setting are 'arson' and 'fire setting'. These are often used interchangeably, despite their different definitions. In the UK, arson is defined by Section 1(2) of the criminal Damage Act 1971 as "to destroy or damage property intending thereby to endanger the life of another, or being reckless as to whether the life of another would thereby be endangered" (The Crown Prosecution Service, 2014). Dickens and Sugarman (2012) define 'arson' as a legal term which defines the specific criminal act of intentionally or recklessly setting fire to property or wildland area. The lesser charge of being reckless would apply if intent (to either damage property, or endanger life) cannot be reliably proven. Though definitions of arson vary internationally, aA $\underline{\underline{A r s o n} \text { is treated }}$ extremely seriously by criminal justice agencies throughout the world, with sentences for convicted arsonists ranging upwards from ten years to life imprisonment (Curtis, McVilly, \& Day, 2013). This reflects the significant harms associated with arson, and the high costs to the community these offences incur.

Whereas aAn arsonist is someone who has been convicted of the crime of $\operatorname{arson}_{2}+$ Tthe term 'fire setting' refers to behaviour characterised by the deliberate 


\section{FIRE SETTING AND INTELLECTUAL DISABILITY}

setting of fires, which has not led to a conviction. This may be due to difficulty identifying the fire setter, the fire not being detected as deliberate, or causing only minimal damage. The perpetrator may be below the age of criminal responsibility, or there is insufficient evidence to gain a conviction. In intellectual disability populations, such offences may also be reported to authorities, but the person may be deemed not guilty because of mental incompetence. Throughout this paper, the term 'arson' will be used to describe an individual(s) who has been those convicted of the crime of arson, and 'fire setting' where there is a record of fire setting behaviour, which has not led to a conviction of arson.

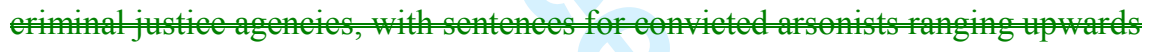
from life imprisonment(Cuntis, MeVilly, \& Day, 2013). This reflects the signifieant harms associated with arson, and the high costs thecommmity these effenestint

It is often reported that the prevalence of arson and fire setting is higher among people with intellectual disabilities (e.g. Simpson, \& Hogg, 2001). A number of studies have reported the prevalence rates of arson, and fire setting amongst those with intellectual disability, and vice versa (See Table 1). As Table 1 details, these prevalence rates vary widely, particularly between community, and specialist intellectual disability inpatient services. Further, these estimates of prevalence are confounded by numerous methodological issues (Taylor, Thorne, Roberston, \& Avery, 2002; Devapriam, \& Bhaumik, 2012) including variations in the definition of intellectual disability, differences between study settings and the reporting of highly selected populations (e.g. prisons and hospitals). It is noted that those with intellectual disability can have a lesser ability to conceal their actions, and are more likely to be caught and arrested for their crimes when they do occur. On the other hand, what 


\section{FIRE SETTING AND INTELLECTUAL DISABILITY}

would be classified as a crime and conviction for someone without intellectual disabilities, may often be labelled as 'challenging behaviour' in someone with intellectual disabilities (Emerson, \& Einfield, 2011, 1995), as carers can be reluctant to report to authorities for a number of reasons.

\section{Insert Table 1}

There is therefore insufficient evidence to establish whether or not fire setting is over- or under-represented in those with intellectual disability (Holland, Clare, \& Mukhopadhyay, 2002). However it is clear that significant numbers of people with intellectual disability come to the attention of health and social, and criminal justice services for reasons of fire setting and arson. Despite these significant numbers, few studies have investigated fire setters in intellectual disability populations. This means that managing the fire setting behaviour of this population can pose significant challenges to services (Lindsay, \& Taylor, 2005). However, a number of servicebased studies have been reported, which have investigated the characteristics of those treated within services for reason of arson and fire setting, and also described treatment approaches.

Devapriam, Raju, Singh, Collacott and Bhaumik, (2007) investigated the prevalence, characteristics and predisposing factors for arson in people with intellectual disability in contact with psychiatric services in Leicestershire in England. The authors reported significant comorbidity amongst those who had committed arson, with high rates of major mental illness, and in particular, personality disorder. Roughly half of the sample had set fires on multiple occasions, and $70 \%$ could be described as versatile offenders, having committed other types of offences. It was also noted that those who had committed arson were not uniformly processed by the 


\section{FIRE SETTING AND INTELLECTUAL DISABILITY}

criminal justice system, with only a fifth of the group going to prison. The majority received hospital orders, whereas a minority received no sanctions for their actions.

A number of studies have described psychological interventions for the treatment of fire setting behaviour. Taylor et al (2002) evaluated the impact of a broadly cognitive behavioural, 40-session group-based intervention on 14 men and women with mild and borderline intellectual disability, who had convictions for arson and were detained in a hospital low secure service. The treatment aimed to reduce fire interest and attitudes associated with fire-setting behaviour. Participants were assessed pre- and post-treatment on a number of fire-specific, anger, self-esteem and depression measures. Following treatment, significant improvements were found in all areas assessed, excepting depression. Performances on these measures over a longer follow up period were not reported.

The same group of authors (Taylor et al., 2006) reported a study on a group of six women detained in a specialist forensic intellectual disability service in England. Although pre and post measures of fire setting interest and attitudes were taken, the sample size was too small to determine whether the treatment had any significant group effect. Therefore the authors qualitatively described the treatment reports of each individual engaged in treatment, as well as a two-year follow up of any recorded fire setting behaviour in the individuals discharge placement. All but one of the participants were recidivist fire-setters, and several had set tens of fires in the past. Five of the six study participants had moved from secure to open community placements following completion of the programme and none were reported to have set any fires at 2-year follow-up, although those discharged continued to receive staff support and supervision to varying degrees. Although the authors note the drawbacks of their study, they concluded that female fire-setters with intellectual disabilities can 


\section{FIRE SETTING AND INTELLECTUAL DISABILITY}

successfully engage in and benefit from therapy, reflected by an absence of firesetting behaviour in the short to medium term.

Studies have investigated the clinical and forensic characteristics of arsonists and fire-setters in general mental health populations. Tyler and Gannon (2012) recently reviewed the literature on male fire setters with mental disorder, and comprehensively described the socio-demographic, developmental, personality, neuropsychological and biological factors associated with this behaviour (See Box 1). Arguably, many of these factors (deprived social backgrounds, disruptive childhoods, sexual and physical abuse, poor social skills, etc.) are not specific to fire setters and may be found in other offender groups.

\section{Insert Box 1}

This paper aims to investigate the clinical, forensic and treatment outcome variables associated with those with a history of fire setting behaviour treated in a forensic hospital setting for people with intellectual disability. Those with a history of fire setting will also be compared to those without on the same variables.

\section{Method}

This study was part of a wider service evaluation project of a 64 bedded specialised forensic inpatient service in England, for people with mild intellectual disability and offending behaviour. All inpatients treated within the service over a 6year period were included in the study. Retrospective data collection from the case files was done by three authors (R.A., I.G., S.H.) who had treated these patients in their capacity as Consultant Psychiatrists. Definitions of the variables, and how each was measured are as follows:

\section{Clinical variables}

Age and Gender: Patients' age and gender were recorded. 


\section{FIRE SETTING AND INTELLECTUAL DISABILITY}

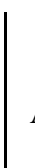

Diagnosis: The service had an established structure of assessments (Selby, \&

Alexander, 2004) and used ICD-10 diagnostic criteria to generate a diagnosis for each patient (World Health Organization, 1992). This covered the degree and cause of ID, pervasive developmental (autistic spectrum) disorders, personality disorders, mental illnesses, harmful use or dependence on alcohol or illicit drugs, physical disorders, psychosocial factors and behavioural problems. While not adopting the hierarchical approach to differential diagnosis of behavioural difficulties favoured by the Diagnostic Criteria - Learning Disability, this system nevertheless captures the extensive comorbidity experienced by offenders with ID (DC-LD; Royal College of Psychiatrists, 2001).

The presence of abuse: Evidence of either a child protection, or protection of a vulnerable adult response by social services had to be present before the experience of abuse was recorded as either probable or definite. This approach is similar to that adopted by Flynn, Matthews, and Hollins (2002).

\section{Forensic variables}

Type of detention: All patients admitted to the service are detained under the Mental Health Act 1983 for England and Wales. Although all patients had some type of offending behaviour, not all had been through the criminal justice process. For the study, Sections 35-38, 47 and 48 of the Mental Health Act, where the detention order is made either by a court or by the Ministry of Justice were designated as 'criminal sections'. In addition, the study recorded the presence of any 'restriction orders', a provision under the Mental Health Act 1983 where the power to discharge patients is taken away from the treating clinician and given to either Mental Health Review Tribunals or the Ministry of Justice. 


\section{FIRE SETTING AND INTELLECTUAL DISABILITY}

Past convictions: Three categories of past convictions were recorded;

violentce offences (those involving interpersonal violence), sexual offences and arson offences.

Past history of aggression: Patients' histories of aggression were recorded (as present or absent) according to six parameters: verbal aggression, aggression to people, aggression to property, aggression to self, sexual aggression and history of fire setting.

Arson / Fire Setting definition - The two terms commonly used to describe deliberate fire setting are 'arson' and 'fire setting'. These are often used interchangeably, despite their different definitions. The present study covers both those with a history of fire setting, and those convicted of arson. A fire setting history was defined as the presence of any type of fire setting behaviour recorded within the patient's case history. This was to capture those whose fire setting behaviour had not been processed by the criminal justice system, as well as those with a recorded arson offence.

\section{Treatment outcome variables}

Institutional aggression: Use of seclusion, physical intervention and intensive observation periods were used as proxy measures for institutional aggression. Data on these interventions was only available for 113 patients treated within the first 4 years covered by the study. The total number of each intervention was divided by the total number of months of inpatient stay for each patient, and an average monthly intervention figure was generated.

Length of stay and direction of care pathway: For the 77 patients who were discharged from the service during the study period, the average duration of hospital stay and a measure of treatment success was gathered. Treatment success was defined 


\section{FIRE SETTING AND INTELLECTUAL DISABILITY}

by whether the patient was discharged to a setting of a lower level of security. A 'poor' outcome was defined as a discharge to a setting of the same or a higher level of security.

\section{Ethics}

Ethical approval was sought from the Norfolk (1) Research Ethics Committee which advised the project did not need to be ethically reviewed under the terms of the Governance Arrangements for Research Ethics Committees in the UK, as it was service development. Findings from the project and the method have been described earlier (Alexander, Green, O’Mahony, Gunaratna, Gangadharan, \& Hoare, 2010).

Formatted: Not Highlight

\section{Statistical analysis}

Those with a fire setting history were compared to those without a fire setting history on a number of clinical, forensic and treatment outcome variables. Chi-square and Fishers exact tests were used for comparison of categorical variables and MannWhitney U-test for comparison of means. Non-parametric tests were used when data did not meet the statistical assumptions for parametric tests. Data was analysed using SPSS - Version 20.

\section{Results}

There were a total of 138 patients, 109 men and 29 women. Of this group, 30 had a history of fire setting, a prevalence of approximately $22 \%$. Those with a fire setting history $(n=30)$ were compared to those without $(n=108)$.

Table 2 shows the comparison between the two groups on the clinical variables measured. Of the fire setting group, $80 \%(n=24)$ had a personality disorder (dissocial or emotionally unstable), $70 \%(n=21)$ had experienced abuse, $46 \%(n=$ 14) a major mental illness (psychosis, bipolar disorder or major depression), 40\% ( $n=$ 12) harmful use or dependence on alcohol and / or illicit drugs and $20 \%(n=6)$ a 


\section{FIRE SETTING AND INTELLECTUAL DISABILITY}

pervasive developmental (autistic spectrum) disorder. The experience of abuse ( $p=$ $0.026)$ and a diagnosis of personality disorder $(p=0.03)$ were significantly more common in the fire setting group.

\section{Insert Table 2}

Table 3 highlights variables related to the patients' forensic histories and offending behaviours. Of the 30 fire setters, only $14(47 \%)$ had received a criminal conviction for arson. Fire setters were more likely than the non-fire setters to have had a past violencet conviction $(p=.007)$, while there were no differences on past convictions for sexual offences.

\section{Insert Table 3}

Table 4 displays the comparisons between groups upon the three measures of treatment outcome; institutional aggression, duration of hospital stay and direction of the care pathway. There were no significant differences between groups on measures of institutional aggression. The findings related to length of stay and direction of care pathway should be treated with caution, due to the small numbers of discharged patients within the fire setting group. Of the 30 fire setters treated over the six year period covered by the study, eight were discharged. These patients appear to have had a length of stay significantly shorter than that of the non-fire setter group. All eight had a good outcome, with two going into the community on a guardianship order and the other six to hospital settings of a lower level of security. However, when looking at the group of patients who had not yet been discharged, there were no significant differences between the two groups on length of stay.

Insert Table 4

\section{Discussion}




\section{FIRE SETTING AND INTELLECTUAL DISABILITY}

This service evaluation paper provides a preliminary exploration of the clinical, forensic and treatment outcome factors associated with fire setters and arsonists admitted to one forensic intellectual disability service in the UK. There are a number of limitations of the study. The service evaluation methodology meant only routinely collected retrospective data could be included, which limited the number of variables which could be examined. Future, prospective work could focus on examining hypotheses driven by previous research, e.g. Tyler and Gannon (2012).

The sample was drawn from a single service and hence one needs to be cautious about the generalisability of the findings. Replicating this process in a prospective manner, involving more services on a regional or national basis would help further our understanding of this group.

However, the data reflects the clinical and forensic characteristics, and treatment outcomes of patients with a history of fire setting, treated over a six year period, about which there is very limited published literature. Findings provide an insight into the differences and similarities between fire setters and non-fire setters in this population, and are discussed in reference to populations without intellectual disability, as reported in previous research.

The key finding of the study was that fire setting behaviour amongst this population was associated with extensive psychiatric co-morbidity. While all patients had an intellectual disability, there was also very high prevalence of personality disorder, major mental illness, harmful use of alcohol / illicit drugs, and autistic spectrum disorder. The fire setting group had experienced significantly more physical and sexual abuse than those without a fire setting history. Increased rates of morbidity in fire setters have been described previously (Devapriam, Raju, Singh, Collacott, \& Bhaumik, 2007; Tyler, \& Gannon, 2012). The available data did not allow us to tease 


\section{FIRE SETTING AND INTELLECTUAL DISABILITY}

out whether fire-setting was directly related to the psychopathology associated with these diagnoses. This may be something to explore in studies with larger sample sizes, drawn from multiple sites. Clarifying that relationship will help to decide whether the focus of treatment needs to be the co-morbid mental health condition rather than the offence-specific therapeutic work, or a combination of both.

As reported in previous research (e.g. Taylor, et al., 2006; Devapriam, Raju, Singh, Collacott, \& Bhaumik, 2007), less than half of those with a fire setting history had a conviction for arson. This is probably because the blurred dividing line between criminal, and challenging behaviour in people with intellectual disability, which affects the reporting and recording of such behaviour (Holland, Clare, \& Mukhopadhyay, 2002). This finding underscores the importance of systematic history taking when undertaking risk assessment for individuals with intellectual disability.

The fire-setting group had significantly more violentce convictions than those in the non-fire-setting group. There were no differences between groups regarding their past histories of aggression, or institutional aggression, with rates equally high in both groups. These findings contrast with earlier conceptualisations of arsonists and fire setters, as unlikely to engage in interpersonal violence, due to the passive conflict management strategies typical of this group (Jackson, Hope, \& Glass, 1987; Tyler, \& Gannon, 2012). Indeed, past authors have described fire setters and arsonists as 'model prisoners' for this reason (Hurley, \& Monahan, 1969). It is unclear whether these findings relate to the nature of this particular sample, e.g., due to the high prevalence of personality disorder. At present, there are no existing studies from forensic intellectual disability services available for comparison, although studies from community intellectual disability settings report a high proportion of the fire 


\section{FIRE SETTING AND INTELLECTUAL DISABILITY}

setters committing other types of offences (Devapriam, Raju, Singh, Collacott, \& Bhaumik, 2007).

Rates of arson and fire setting within forensic intellectual disability services are high, demonstrating a clear treatment need. A number of psychological treatment groups for people with intellectual disability and fire setting behaviour have been reported (e.g. Taylor, Thorne, Roberston, \& Avery, et al., 2002; Jervis, 2012; Tranah, $\&$ Nicholas, 2013). However, the high prevalence of psychiatric morbidity in this sample, such as schizophrenia raises questions about the most appropriate sequence of therapeutic interventions. Within the service where the study took place, patients progress through a ten-point treatment programme (see Box 2). This approach is based on the treatment pathway for the management of personality disorders in learning disability, suggested by Johnstone (2005), who described a four stage process consisting of assessment and motivational work, interventions including foundation treatments, offence specific treatments and personality disorder symptom reduction treatments, consolidation or relapse prevention and discharge. The programme emphasises the treatment of co-morbid conditions prior to any further work, and introduces participants to strategies and skills to assist with deficits like poor social skills, low self-esteem, poor emotional regulation and problematic interpersonal relationships before starting any offence specific work (e.g. fire setting and arson treatment programmes).

Of the 30 fire setters treated over the six year period covered by the study, eight were discharged. These patients had significantly lower length of stays than the non-fire setters and were successfully discharged to lower levels of security. This could suggest that there may be a sub-group of those with a history of fire setting within this population who respond well to treatment. However, there was a larger 


\section{FIRE SETTING AND INTELLECTUAL DISABILITY}

group with longer lengths of stay, who remained as inpatients. The distinction between these two groups and their different treatment needs requires further exploration. It is therefore recommended that future research investigate this issue, with larger samples drawn from multiple services.

\section{References}

Alexander, R. T., Crouch, K., Halstead, S., \& Piachaud, J. (2006). Long-term outcome from a medium secure service for people with intellectual disability. Journal of Intellectual Disability Research, 50(4) 305-315. doi: 10.1111/j.13652788.2006.00806.x

Alexander, R. T., Green, F. N., O’Mahony, B., Gunaratna, I. J., Gangadharan, S. K., \& Hoare, S. (2010). Personality disorders in offenders with intellectual disability: a comparison of clinical, forensic and outcome variables and implications for service provision. Journal of Intellectual Disability Research, 54(7) 650-658. doi: 10.1111/j.1365-2788.2010.01248.x

Alexander, R. T., Hiremath, A., Chester, V., Green, F. N., Gunaratna, I. J., \& Hoare, S. (2011). Evaluation of treatment outcomes from a medium secure unit for people with intellectual disability. Advances in Mental Health and Intellectual Disabilities, 5(1) 22-32. doi: 10.5042/amhid.2011.0013

Alexander, R. T., Piachaud, J., Odebiyi, L., \& Gangadharan, S. K. (2002). Referrals to a forensic service in the psychiatry of learning disability. British Journal of Forensic Practice, 4, 29-33. doi: 10.1108/14636646200200013

Alexander, R._T., Tajuddin, M., \& Gangadharan, S. (2007). Personality Disorders in Intellectual Disability: Approaches to Pharmacotherapy. Mental Health Aspects of Developmental Disabilities, 10(4) 129-135.

14 
FIRE SETTING AND INTELLECTUAL DISABILITY

Bhaumik, S., \& Branford, D. (2005). The Frith Prescribing Guidelines for Adults with Learning Disability. Oxfordshire: Taylor and Francis.

Curtis, A., McVilly, K., \& Day, A. (2012). Arson treatment programmes for offenders with disability: a systematic review of the literature. Journal of Learning Disabilities and Offending Behaviour, 3(4) 186-205. doi:

$10.1108 / 20420921211327347$

Department for Communities and Local Government. (2010). Fire Statistics United Kingdom 2008. Retrieved Dec $5^{\text {th }}, 2012$, from http://www.communities.gov.uk/documents/statistics/pdf/1780609.pdf

Devapriam, J., \& Bhaumik, S. (2012). Intellectual disability and arson. In G. L. Dickens, P._A. Sugarman \& T. A. Gannon (Eds.), Fire Setting and Mental Health_(pp. 107-125). London: RCPsych Publications.

Dickens, G. L., Sugarman, P. A., \& Gannon, T. A. (2012). Fire Setting and Mentat Health. London: RCPsych Publications.

Emerson, E., \& Einfeld, S. L. (2011). Challenging behaviour: analysis and intervention in people with intellectual disabilities. Cambridge: Cambridge University Press.

Emerson, E. (1995). Challenging Behaviour: Analysis and Intervention in People with Learning Disabilities. Cambridge University Press, Cambridge.

Enayati, J., Grann, M., Lubbe, S., \& Fazel, S. (2008). Psychiatric morbidity in arsonists referred for forensic psychiatric assessment in Sweden. The Journal of Forensic Psychiatry \& Psychology, 19(2) 139-147. doi: $10.1080 / 14789940701789500$

Flynn, A., Matthews, H., \& Hollins, S. (2002). Validity of the diagnosis of personality disorder in adults with learning disability and severe behavioural problems: 


\section{FIRE SETTING AND INTELLECTUAL DISABILITY}

Preliminary study. British Journal of Psychiatry, 180, 543-546. doi: 10.1192/bjp.180.6.543

Hogue, T., Steptoe, L., Taylor, J. L., Lindsay, W. R., Mooney, P., Pinkney, L. . . . O'Brien, G. (2006). A comparison of offenders with intellectual disability across three levels of security. Criminal Behaviour and Mental Health, 16(1) $13-28$.

Holland, T., Clare, I., \& Mukhopadhyay, T. (2002). Prevalence of ‘criminal offending' by men and women with intellectual disability and the characteristics of 'offenders': Implications for research and service development. Journal of Intellectual Disability Research, 46, 6-20. doi: $10.1002 / \mathrm{cbm} .52$

Hearne, S. Garner, K., O’Mahony, B., Thomas, C., \& Alexander, R.T. (2007). The Life Skills group - an introductory multi-modular group programme in forensic learning disability. The British Journal of Forensic Practice, 9(2) 313. doi: $10.1108 / 14636646200700008$

Hurley, W., \& Monahan, T. M. (1969). Arson: the criminal_and the crime. British Journal of Criminology, 9, 4-21.

Jackson, H. F., Hope, S., \& Glass, C. (1987). Why Are Arsonists Not Violent Offenders? International Journal of Offender Therapy and Comparative Criminology, 31, 143-151. doi: 10.1177/0306624X8703100207

Jervis, V. (2012, April). Development of the Phoenix Fire Setting Group. Paper session at the 11th International Conference on the Care and Treatment of Offenders with a Learning Disability, Northumbria University.

Johnstone, S. (2005, April). Intellectually disabled offenders with personality disorder. Paper session at the 4th International Conference on the Care and 


\section{FIRE SETTING AND INTELLECTUAL DISABILITY}

Treatment of Offenders with a Learning Disability, University of Central Lancashire, Preston.

Lindsay, W. R., \& Taylor, J. L. (2005). A selective review of research on offenders with developmental disabilities: Assessment and treatment. Clinical Psychology and Psychotherapy, 12, 201-214. doi: 10.1002/cpp.450

Lindsay, W., Carson, D., O'Brien, G., Holland, A._J., Johnstone, S., Taylor, J. L., . . . Young, S. (2010). The relationship between assessed risk and service security level for offenders with intellectual disability. The Journal of Forensic Psychiatry \& Psychology, 21(4) 537-548. doi: 10.1080/14789941003653212

Office of the Deputy Prime Minister. (2003). Arson Control Forum annual report. London: Author.

Plant, A., McDermott, E., Chester, V., \& Alexander, R.T. (2011). Substance misuse among offenders in a forensic intellectual disability service. Journal of Learning Disabilities and Offending Behaviour, 2(3) 127-136. doi: $10.1108 / 20420921111186589$

Petty, M., Rolfe, J., \& Chester, V. (2013). Moving from feelings of terror to 'I like learning maths': An evaluation of a teaching activity in a forensic intellectual disability setting. Quality Network for Forensic Mental Health Low Secure Newsletter, Issue 3, 3-5.

Puri, B. K., Baxter, R., \& Cordess, C. C. (1995). Characteristics of fire-setters. A study and proposed multiaxial psychiatric classification. The British Journal of Psychiatry, 166(3) 393-396. doi: 10.1192/bjp.166.3.393

Royal College of Psychiatrists (2001). DC-LD: Diagnostic criteria for psychiatric disorders for use with adults with learning disabilities/mental retardation. London: Author. 


\section{FIRE SETTING AND INTELLECTUAL DISABILITY}

Selby, G., \& Alexander, R._T. (2004). Care programme approach in a forensic learning disability service. The British Journal of Forensic Practice, 6(4) 2631. doi: $10.1108 / 14636646200400024$

Simpson, M. K., \& Hogg, J. (2001). Patterns of offending among people with intellectual disability: a systematic review. Part I: methodology and prevalence data. Journal of Intellectual Disability Research, 45(5) 385-396.

Smith, A., Petty, M., Oughton, I., \& Alexander, R._T. (2010). Establishing a workbased learning programme: vocational rehabilitation in a forensic learning disability setting. British Journal of Occupational Therapy, 73(9) 431-436. doi: $10.4276 / 030802210 \times 12839367526174$

Taylor, J. L., Thorne, I., Roberston, A., \& Avery, G. (2002). Evaluation of a group intervention for convicted arsonists with mild and borderline intellectual disabilities. Criminal Behaviour and Mental Health, 12, 282-293. doi: $10.102 / \mathrm{cbm} .506$

Taylor, J. L., Robertson, A., Thorne, I., Belshaw, T., \& Watson, A. (2006). Responses of Female Fire-Setters with Mild and Borderline Intellectual Disabilities to a Group Intervention. Journal of Applied Research in Intellectual Disabilities, 19, 179-190. doi: 10.1111/j.1468-3148.2005.00260.x

The Crown Prosecution Service (2014). Criminal Damage. Available from: http://www.cps.gov.uk/legal/a to c/criminal damage/\#a14 Accessed $2^{\text {nd }}$ June $\underline{2014}$.

Thomas, C., Kitchen, D., \& Smith, A. (2005). The management of aggression care plans: implementation and efficacy in a forensic learning disability service. The British Journal of Forensic Practice, 7(2) 3-9. doi: Formatted: Font: (Default) Times New Roman, 12 pt, Font color: Auto

Formatted: Font: (Default) Times New Roman, 12 pt

Formatted: Font: (Default) Times New Roman, 12 pt, Font color: Auto

Formatted: Font: (Default) Times New Roman, 12 pt, Font color: Auto

Formatted: Font: (Default) Times New Roman, 12 pt, Font color: Auto, Superscript

Formatted: Font: (Default) Times New Roman, 12 pt, Font color: Auto 


\section{FIRE SETTING AND INTELLECTUAL DISABILITY}

Tranah, T., \& Nicholas, J. (2013). Interventions for young people with intellectual disabilities who commit arson. Advances in Mental Health and Intellectual Disabilities, 7(2) 72-81. doi: 10.1108/20441281311310162

Tyler, N., \& Gannon, T. A. (2012). Explanations of firesetting in mentally disordered offenders: A review of the literature. Psychiatry, 75(2) 150-66. doi: $10.1521 /$ psyc. 2012.75 .2 .150

Wheeler, J. R., Holland, A. J., Bambrick, M., Lindsay, W. R., Carson, D., Steptoe, L., ... O'Brien, G. (2009). Community services and people with intellectual disabilities who engage in antisocial or offending behaviour: referral rates, characteristics, and care pathways. Journal of Forensic Psychiatry \& Psychology, 20(5) 717-740. doi: 10.1080/14789940903174048

World Health Organization. (2008). ICD-10: International statistical classification of diseases and related health problems (10th Rev. ed.). New York, NY: WHO. 
FIRE SETTING AND INTELLECTUAL DISABILITY

Table 1: Reported Prevalence of Arson and Fire Setting in Intellectual Disability Populations.

\begin{tabular}{|c|c|c|c|c|c|}
\hline Study & Sample / Population & $\begin{array}{c}\text { Total } \\
n\end{array}$ & Country & Definition & $\begin{array}{c}\text { Reported } \\
\text { Prevalence }\end{array}$ \\
\hline Puri et al. (1995) & $\begin{array}{l}\text { People with intellectual disability referred to a forensic } \\
\text { psychiatry service }\end{array}$ & 36 & England & Fire-setting & $3 \%$ \\
\hline Taylor (2002) & $\begin{array}{l}\text { Men with intellectual disability admitted to an inpatient forensic } \\
\text { service }\end{array}$ & 129 & England & Arson & $25 \%$ \\
\hline Alexander et al. (2002) & Referrals to a forensic intellectual disability service & 79 & England & Arson & $10.4 \%$ \\
\hline Alexander et al. (2006) & $\begin{array}{l}\text { Inpatients discharged from a medium secure intellectual } \\
\text { disability service. }\end{array}$ & 64 & England & Arson & $15 \%$ \\
\hline Hogue et al. (2006) & $\begin{array}{l}\text { Offenders with intellectual disability from three levels of } \\
\text { security, medium }(\underline{\mathrm{M})} \text {, low } \underline{(\mathrm{L})} \text {, community } \underline{(\mathrm{Com})} \text {. }\end{array}$ & 212 & $\begin{array}{l}\mathrm{UK}-3 \\
\text { regions }\end{array}$ & Arson & $\begin{array}{l}\mathrm{M} / \mathrm{L}-21.4 \% \\
\mathrm{Com}-2.9 \%\end{array}$ \\
\hline Devapriam et al. (2007) & $\begin{array}{l}\text { Adults }(19+) \text { with intellectual disability who had been in contact } \\
\text { with community psychiatric services during a } 20 \text { year period. }\end{array}$ & 1100 & England & Arson & $1.36 \%$ \\
\hline Enayati et al. (2008) & $\begin{array}{l}\text { Arsonists referred for inpatient forensic psychiatric examination } \\
\text { over a five-year period (1997-2001). }\end{array}$ & 214 & Sweden & Arson & $9.8 \%$ \\
\hline Wheeler et al. (2009) & Referrals to community learning disability team. & 237 & $\begin{array}{l}\mathrm{UK}-3 \\
\text { regions }\end{array}$ & Fire starting & $1 \%$ \\
\hline $\begin{array}{l}\text { Alexander et al. (2010; } \\
\text { 2011) }\end{array}$ & Secure / forensic inpatient intellectual disability service & 138 & England & $\begin{array}{l}\text { Arson } \\
\text { Fire setting }\end{array}$ & $\begin{array}{l}10 \% \\
22 \%\end{array}$ \\
\hline Lindsay et al. (2010) & $\begin{array}{l}\text { Offenders with intellectual disability accepted into forensic } \\
\text { services }\end{array}$ & & & Fire setting & $10 \%$ \\
\hline
\end{tabular}


FIRE SETTING AND INTELLECTUAL DISABILITY

Table 2: Comparison between those with Fire Setting histories and those Without: Clinical Variables

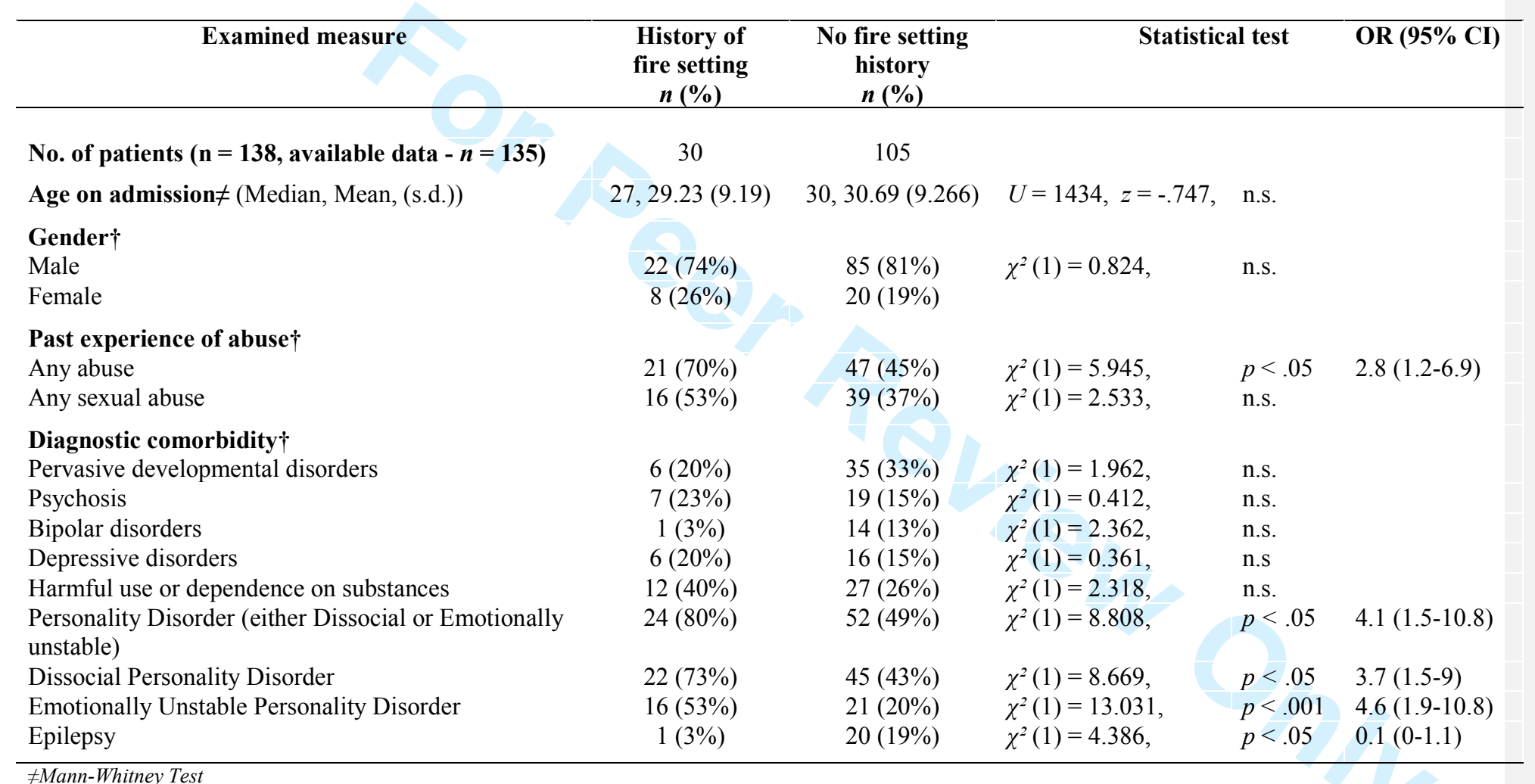

Fishers Exact Test 
FIRE SETTING AND INTELLECTUAL DISABILITY

Table 3: Comparison between those with Fire Setting Histories and those Without: Forensic variables

\begin{tabular}{|c|c|c|c|c|c|}
\hline Examined measure & $\begin{array}{l}\text { History of } \\
\text { fire setting } \\
\quad n(\%)\end{array}$ & $\begin{array}{l}\text { No fire } \\
\text { setting } \\
\text { history } \\
n(\%) \\
\end{array}$ & Statistical te & & OR $(95 \%$ CI $)$ \\
\hline $\begin{array}{l}\text { Number of patients } \\
(n=138, \text { available data }-n=135)\end{array}$ & 30 & 105 & & & \\
\hline $\begin{array}{l}\text { Legal status on admission } \dagger \\
\text { Detentions under 'criminal' sections } \\
\text { Detentions with a restriction order }\end{array}$ & $\begin{array}{l}18(60 \%) \\
10(33 \%)\end{array}$ & $\begin{array}{l}35(33 \%) \\
15(14 \%)\end{array}$ & $\begin{array}{l}\chi^{2}(1)=6.958 \\
\chi^{2}(1)=5.610\end{array}$ & $\begin{array}{l}p<.05 \\
p<.05\end{array}$ & $\begin{array}{l}3(1.3-6.9) \\
3(1.2-7.6)\end{array}$ \\
\hline $\begin{array}{l}\text { History of convictions } \dagger \\
\text { Conviction for violencet offences } \\
\text { Conviction for sex offences } \\
\text { Conviction for arson }\end{array}$ & $\begin{array}{l}18(60 \%) \\
6(20 \%) \\
14(47 \%)\end{array}$ & $\begin{array}{l}34(14 \%) \\
22(21 \%) \\
0\end{array}$ & $\begin{array}{l}\chi^{2}(1)=7.312 \\
\chi^{2}(1)=0.019 \\
\chi^{2}(1)=54.669\end{array}$ & $\begin{array}{l}p<.05 \\
\text { n.s. } \\
p<.001\end{array}$ & $3.1(1.4-7.2)$ \\
\hline $\begin{array}{l}\text { History of aggression } \uparrow \\
\text { Verbal aggression } \\
\text { Aggression towards people } \\
\text { Aggression towards property } \\
\text { History of sexual aggression } \\
\text { Aggression towards self }\end{array}$ & $\begin{array}{l}29(97 \%) \\
26(87 \%) \\
25(83 \%) \\
19(63 \%) \\
27(90 \%)\end{array}$ & $\begin{array}{l}100(95 \%) \\
98(93 \%) \\
97(92 \%) \\
50(48 \%) \\
83(79 \%)\end{array}$ & $\begin{array}{l}\chi^{2}(1)=0.112 \\
\chi^{2}(1)=1.386 \\
\chi^{2}(1)=2.195 \\
\chi^{2}(1)=2.306 \\
\chi^{2}(1)=1.855\end{array}$ & $\begin{array}{l}\text { n.s. } \\
\text { n.s. } \\
\text { n.s. } \\
\text { n.s. } \\
\text { n.s. }\end{array}$ & \\
\hline
\end{tabular}


FIRE SETTING AND INTELLECTUAL DISABILITY

Table 4: Comparison between those with Fire Setting Histories and those Without: Treatment Outcome Variables

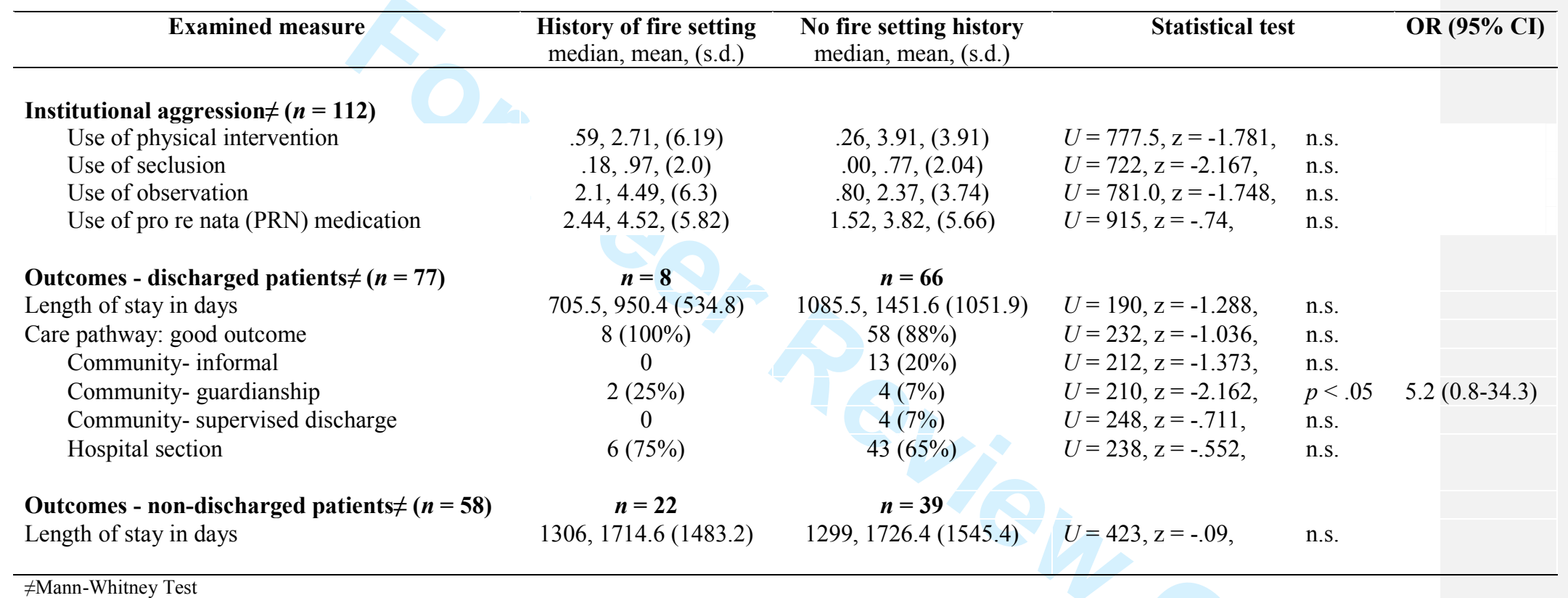


FIRE SETTING AND INTELLECTUAL DISABILITY

Box 1: Factors associated with fire setting in offenders with mental disorders (Tyler \& Gannon, 2012).

\section{Socio-demographic \\ Caucasian \\ Single/Separated \\ Low IQ}

Low socioeconomic status

Low levels of educational attainment

Unemployed/unskilled employment

Background/Developmental

Large family

Absent father

History of physical/sexual abuse

Parental alcoholism

Previous engagement with mental health services

History of truanting from school

Previous convictions for fire-setting

History of juvenile fire-setting

History of parental mental illness

\section{Personality \& Other Associated Traits}

Lack social skills

Relationship difficulties

Low levels of assertiveness

Low levels of intelligence

Low self esteem

Impulsive

Low levels of interpersonal aggression

\section{Neuropsychological \& Biological}

Klinefelter's syndrome

Reactive hypoglycemic levels

Decreased blood glucose levels

Epilepsy

Neurotransmitter abnormality

Brain injury

Low MHPG Levels

Abnormal EEG readings

\section{Psychosis \& Psychiatric Diagnosis}

Depression

Schizophrenia and other psychotic disorders

Mania

Borderline \& Antisocial Personality Disorders

Developmental Disorders

Bipolar 


\section{FIRE SETTING AND INTELLECTUAL DISABILITY}

\section{Box 2: The Ten Point Treatment Plan}

1. A multi-axial diagnostic assessment that covers the degree of learning disability, cause of learning disability, pervasive developmental disorders, other developmental disabilities, mental illnesses, substance misuse or dependence, personality disorders, physical disorders, psychosocial disadvantage and types of behavioural problems (Selby, \& Alexander, 2004)

2. A psychological formulation, developed collaboratively with the patient.

3. Risk assessments (Selby, \& Alexander, 2004)

4. A management of aggression care plan (Thomas, Kitchen, \& Smith, 2005)

5. Appropriate pharmacotherapy that targets both co-morbid mental illnesses and the predominant symptom clusters that are problematic (Bhaumik, \& Branford, 2005; Alexander, Tajuddin, \& Gangadharan, 2007)

6. Treatment of any physical disorders.

7. Individual or group psychotherapy that may include motivational work, supportive therapy, addressing co-morbidities like substance misuse or issues like bereavement and other "foundation treatments" (Hearne, Garner, O'Mahony, Thomas, \& Alexander, 2007; Plant, McDermott, Chester, \& Alexander, 2009)

8. Offence specific therapies, education, skills acquisition and occupational/vocational rehabilitation: (Smith, Petty, Oughton, \& Alexander, 2010; Petty, Rolfe, \& Chester, 2013).

9. Community participation through a system of graded escorted, shadowed and unescorted leave periods

10. Preparation for transition. 